\title{
Diagnostic Value of Presepsin in Elderly Patients with COPD Exacerbation
}

\author{
Sally M.A. habib ${ }^{a}$, Hoda A. Abdelsattar ${ }^{b}$, Marwa A. Abdel Gawad ${ }^{a}$, Doha Rasheedy ${ }^{a}$, Shereen \\ M. Mousa ${ }^{a}$, Hala S. Sweed ${ }^{a}$ \\ a Geriatrics and Gerontology department, Faculty of Medicine, Ain Shams University. \\ b Clinical Pathology department, Faculty of Medicine, Ain Shams University.
}

\begin{abstract}
Background: Chronic obstructive pulmonary disease (COPD) is associated with systemic low-grade inflammation which increases further in exacerbation states. CD14 is a glycoprotein expressed on monocytes and macrophages and its soluble fraction, presepsin, is present in blood and produced in association with inflammation and infections.

Aim: to assess the diagnostic value of presepsin in elderly patients with acute exacerbation of COPD (AECOPD).

Methods: The study population consisted of 30 patients with AECOPD, 30 patients with stable COPD and 30 controls. Serum presepsin levels, complete blood counts, C-reactive protein (CRP) and erythrocytes sedimentation rate $(E S R)$ were measured in all subjects. Short-term outcomes i.e. length of hospital stay, intensive care unit admission and mortality were recorded.

Results: Total leucocytic count (TLC), CRP and presepsin levels were significantly higher in exacerbation group $(p<0.001)$ with no significant difference between stable and control groups, while ESR was significantly different among the 3 groups $(p<0.001)$. After regression analysis of confounding factors, prespsin, CRP and ESR were increased in stable COPD and AECOPD while TLC was increased in AECOPD. In ROC analysis, presepsin cut-off value was $\geq 0.5 \mathrm{ng} / \mathrm{ml}$ for differentiating exacerbation from stable COPD (area under ROC curve $=0.997$, confidence interval: $0.000-1.000, P<0.001)$. Presepsin had positive correlations with respiratory rate $(p=0.049)$ and length of hospital stay $(p<0.001)$. Presepsin levels were also higher in patients with pneumonia $(p=0.002)$, respiratory failure $(p=0.024)$ and in cases admitted to the ICU $(p=0.016)$.
\end{abstract}

Conclusion: Presepsin can be a valuable biomarker to diagnose AECOPD in elderly patients.

Keywords: biomarker, chronic obstructive pulmonary disease, exacerbation, presepsin.

\section{Background}

Chronic Obstructive Pulmonary Disease (COPD) is considered a public health challenge and a great cause of morbidity and mortality in the world. It was found that the number of cases with COPD was 384 million in 2010 , with a global prevalence of $11.7 \%{ }^{1}$

The prevalence of COPD in elderly increases with age and may reach up to $15 \%$ in those over 65 years of age. $^{2}$

With aging of the population and continued exposure to the risk factors of COPD, the prevalence of COPD is expected to rise over the next 30 years. $^{3}$ By the year 2030 there may be more than 4.5 million deaths annually from COPD and related conditions. ${ }^{4,5,6}$

The natural history of COPD is often interrupted by periodic exacerbations which are important events in the chronic and progressive course of COPD. Frequent exacerbations could reduce quality of life, speed disease progression, and increase the risk of death. ${ }^{8}$ Exacerbation is defined as an acute change in a patient's baseline dyspnea, cough, or sputum that is beyond normal variability, and that is sufficient to warrant a change in therapy. ${ }^{9}$

In patients with known COPD, exacerbations occur an average of 1.3 times per year and they range in severity from transient declines in functional status to fatal events. ${ }^{10}$

The most common identifiable causes of COPD exacerbations include bacterial and viral infections, air pollution (e.g., tobacco smoke, occupational exposures, ozone), cold weather and interruption of regular treatment. However, one third of exacerbations have no identifiable cause. ${ }^{11}$

Owing to their heterogeneity and the lack of available diagnostic laboratory tests, COPD exacerbations are 
often diagnosed based on clinical assessment, which is subjective and variable within and across physicians. ${ }^{\mathbf{1 2}}$ Instead, biomarkers may better reflect disease activity and fluctuate in accordance with disease state. Therefore, a "biomarker" is needed to achieve an objective verification of exacerbations. ${ }^{13}$

It is now well known that a major factor in the pathogenesis of COPD is chronic inflammation of the small airways, caused by inhalation of particles and gases, which is further increased during acute exacerbations ${ }^{\mathbf{1 4}}$ and this inflammatory process spills over into the systemic circulation which may result in an 'inflammatory signature' in blood related to COPD. 15,16

Accordingly, there has been great interest in developing biomarkers that are specific to the inflammatory process in COPD and can be related to important clinical health outcomes such as exacerbations and mortality. While levels of these biomarkers may be altered when comparing stable COPD patients to normal controls, further disturbances may be observed in the acute setting of an exacerbation. ${ }^{17}$

Presepsin (sCD14-ST) is the soluble N-terminal fragment of the cluster of differentiation (CD) marker protein CD14. CD14 is a multifunctional glycoprotein expressed mainly on the membrane surface of monocytes/macrophages which serves as a specific receptor for complexes of lipopolysaccharides (LPSs) and LPS-binding proteins (LBPs). ${ }^{\mathbf{1 8}}$

When the proinflammatory signaling cascade against infectious agents is activated, soluble form of CD14 (presepsin) is produced and released into circulation either by secretion following phagocytosis or through proteolytic cleavage on activated monocytes. ${ }^{19,20}$

Elevation of serum presepsin levels has been recognized as a specific, early phase biomarker for sepsis, especially in the field of critical care medicine. $\mathbf{1 8 , 2 1 , 2 2}$

However, to our knowledge, the effectiveness of presepsin as a biomarker in predicting COPD exacerbation has not been investigated so far. The aim of the current study was to assess the diagnostic accuracy of presepsin in elderly patients with COPD exacerbation.

\section{METHODS}

Study Design: Cross-sectional study was conducted in Ain-Shams University Hospital at outpatient clinics. The study included 120 older adults $\geq 60$ yrs. old (males and females) who attended outpatient clinics. All the patients were able to walk independently and their condition was stable. Patients who had acute illness or overt dementia were excluded.

\section{METHODS:}

In this case control study, 90 elderly (60 years and older) participants were recruited from September 2017 to September 2019 from the community and from the inpatient wards and outpatient clinics of Ain Shams
University Hospitals, Cairo, Egypt.

The subjects were divided into three groups; Group A: 30 patients with COPD during exacerbation; Group B: 30 patients with stable COPD who had not been hospitalized for exacerbation of the disease for at least 2 months before; and Group C: 30 subjects as a control group who were lifelong nonsmokers, free from any lung disease, with normal spirometry and with no history of atopy.

Diagnosis of COPD (for group A and B) was made according to GOLD criteria, as follows: Presence of symptoms of dyspnea, chronic cough and sputum production, and history of exposure to risk factors for the disease. Diagnosis is confirmed by spirometry showing post-bronchodilator FEV1/FVC $<0.70 .{ }^{23}$

COPD exacerbations (for group A) was defined according to GOLD criteria as those with acute worsening of respiratory symptoms (worsening of dyspnea sensation, coughing, or sputum production that can become purulent) that result in additional therapy.

Participants who refused to participate or had any lung disease other than COPD or patients who had Conditions that affect presepsin levels such as recent major trauma or surgical intervention, any other site infection, autoimmune inflammatory disease, malignant cancer of any type, acquired immunodeficiency syndrome, end-stage liver disease and end-stage renal disease were excluded.

Acceptance of ethical committee of faculty of medicine, Ain shams university, and informed oral consent from study subjects were taken. All participants were subjected to history taking and examination. Regarding COPD subjects; exacerbation history including previous hospital admissions was taken and symptom assessment was done through the Modified British Medical Research Council (mMRC) Questionnaire and COPD Assessment Test (CAT). Assessment of the current exacerbation presentation and short-term outcomes were done for group A (COPD exacerbation). Assessment of functional status for all subjects was done through Activities of Daily Living Scale (ADL).

Pulmonary function tests using portable spirometer (FCC ID: TUK-MIR009) were performed for all subjects for the diagnosis of COPD and for staging of severity of airflow limitation according to GOLD guidelines; GOLD stage I [FEV1 $\geq 80 \%$, stage II $[50 \%$ $\leq$ FEV1 <80\%], stage III $[30 \% \leq$ FEV1 <50\%], and stage IV [FEV1 <30\%].

Presepsin was detected in the plasma of all subjects using the enzyme-linked immunosorbent assay (ELISA) with the commercially available Human Presepsin (sCD14-ST) ELISA Kit, according to the manufacturer's instructions (Wuhan Fine Biotech Co., Ltd). The assay detection range is $0.156-10 \mathrm{ng} / \mathrm{ml}$. The technicians who measured the samples were blinded to the identity of the patient samples. Arterial blood gases (PaCO2 and $\mathrm{PaO} 2$ ), complete blood count (CBC), 
serum C-reactive protein levels and erythrocyte sedimentation rate (ESR) were also measured.

\section{Statistical Methods}

Descriptive statistics were done for quantitative data as minimum\& maximum of the range as well as mean \pm SD (standard deviation) for quantitative normally distributed data, while it was done for qualitative data as number and percentage. Inferential analyses were done for quantitative variables using Shapiro-Wilk test for normality testing, independent t-test in cases of two independent groups with normally distributed data and ANOVA test. In qualitative data, inferential analyses for independent variables were done using Chi square test for differences between proportions and Fisher's Exact test for variables with small expected numbers. Post hoc Bonferroni test was used to find out homogenous groups in multiple significant comparisons.

ROC curve was used to evaluate the performance of different tests differentiate between certain groups. Linear regression model was used to find out independent factors affecting certain conditions. The level of significance was taken at $\mathrm{P}$ value $<0.050$ is significant, otherwise is non-significant.

The collected data were coded, tabulated, and statistically analyzed using IBM SPSS statistics (Statistical Package for Social Sciences) software version 18.0, IBM Corp., Chicago, USA, 2009.

\section{Ethical considerations}

The study was performed in adherence to the principles established by the Declaration of Helsinki and the study methodology was reviewed and approved by the Research Review Board of the Geriatrics and Gerontology Department, Faculty of Medicine, Ain Shams University. Informed verbal consent was obtained from all the participants because some of the participants were illiterate and could not provide a signed consent. The verbal consent was documented in the presence of a next of kin and a nurse. The ethics committee approved using of verbal consent.

\section{Results}

The current study is a case control study. The study population was 90 elderly (60 years and older) who were divided into three groups; Group A: 30 patients with COPD exacerbation; Group B: 30 patients with stable COPD; and Group C: 30 control subjects.

The 3 study groups were matched for age and gender; Male subjects constituted $93.3 \%, 83.3 \%$ and $80 \%$ of the exacerbation, stable and control groups respectively while female subjects constituted $6.7 \%, 16.7 \%$ and $20 \%$. The three studied groups were also matched regarding their functional status (ADL scale) and co(). morbidities (DM, HTN, ISHD, OA, BPH and gastritis). The characteristics and comorbidities of participants in the 3 groups are outlined in Table 1 .

Also, in COPD subjects, there was no significant difference between exacerbation and stable groups regarding COPD duration, risk factors, smoking index, COPD severity, treatment, treatment duration, exacerbation frequency and previous hospitalizations. Similarly, there was no significant difference between the two groups regarding modified MRC scale and CAT score ( $\mathrm{P}$ value $>0.05)$. (data not shown in tables)

Regarding levels of inflammatory markers among the 3 study groups; TLC, CRP and presepsin were significantly higher in exacerbation group $(\mathrm{p}<0.001)$ with no significant difference between stable and control groups, while ESR was significantly different among the 3 study groups; highest in exacerbation, followed by stable and least in control $(\mathrm{p}<0.001)$ (data shown in table 2). After regression analysis of all studied confounding factors, it was found that prespsin, CRP and ESR were increased in stable COPD and exacerbation while TLC was increased in COPD exacerbation (data not shown in tables).

In ROC analysis, the area under the curve was 0.997 (95\% confidence interval [CI]: 0.000-1.000, P<0.001) for presepsin, 0.992 (95\% CI: 0.000-1.000, P<0.001) for CRP, and 0.831 (95\% CI: $0.731-0.931, \mathrm{P}<0.001$ ) for ESR and 0.772 (95\% CI: 0.643-0.900, P<0.001) for TLC in identifying patients with COPD exacerbation, indicating that presepsin and CRP were superior to TLC and ESR and had a high diagnostic performance in differentiating exacerbation from stable COPD (figure $1)$.

The cutoff values of presepsin $\geq 0.5$ and CRP $\geq 10.0$ were found to have the highest diagnostic characteristics in differentiating exacerbation from stable COPD with sensitivity $100 \%$ and $96.7 \%$ respectively and specificity $93.3 \%$ and $100 \%$ respectively (figure 1 ).

The presepsin levels were found to be significantly higher in COPD exacerbation subjects with pneumonia $(\mathrm{p}=0.004)$, subjects admitted to the ICU $(\mathrm{p}=0.016)$ and in those with respiratory failure $(\mathrm{p}=0.024)$ (table 3$)$, which denotes that increase in presepsin levels in serum of exacerbated COPD patients is correlated with the severity of exacerbation.

Presepsin levels showed significant positive correlations with the other studied inflammatory markers [TLC, CRP $(\mathrm{P}<0.001)$ and ESR $(\mathrm{P}=0.039)$ ], respiratory rate $(\mathrm{p}=0.049)$ and length of hospital stay ( $<<0.001$ ) but a significant negative correlation with hemoglobin level $(\mathrm{p}=0.008)$ 
Table (1): Characteristics of the Studied Population:

\begin{tabular}{|c|c|c|c|c|c|}
\hline \multicolumn{2}{|c|}{ Variables } & \multirow{2}{*}{$\begin{array}{c}\begin{array}{c}\text { Exacerbati } \\
\text { on } \\
(\mathbf{N}=\mathbf{3 0})\end{array} \\
66.7 \pm 7.4\end{array}$} & \multirow{2}{*}{$\begin{array}{c}\begin{array}{c}\text { Stable } \\
(\mathbf{N}=30)\end{array} \\
64.2 \pm 4.8\end{array}$} & \multirow{2}{*}{$\begin{array}{c}\begin{array}{c}\text { Control } \\
(\mathbf{N}=30)\end{array} \\
66.3 \pm 5.8 \\
\end{array}$} & \multirow{2}{*}{$\begin{array}{c}\mathbf{P} \\
\wedge 0.260\end{array}$} \\
\hline Age (years) & Mean \pm SD & & & & \\
\hline & Range & $60.0-87.0$ & $60.0-76.0$ & $60.0-81.0$ & \multirow{3}{*}{$\S 0.413$} \\
\hline \multirow[t]{2}{*}{ Sex } & Male & $28(93.3 \%)$ & $25(83.3 \%)$ & $24(80.0 \%)$ & \\
\hline & Female & $2(6.7 \%)$ & $5(16.7 \%)$ & $6(20.0 \%)$ & \\
\hline \multirow{3}{*}{$\begin{array}{l}\text { Cigarette } \\
\text { smoking }\end{array}$} & Never & $2(6.7 \%) \mathrm{a}$ & $5(16.7 \%) \mathrm{a}$ & $30(100.0) b$ & \multirow[t]{3}{*}{$\#<0.001 *$} \\
\hline & Ex-smoker & $9(30.0 \%)$ & $6(20.0 \%)$ & $0(0.0 \%)$ & \\
\hline & Smoker & $19(63.3 \%)$ & $19(63.3 \%)$ & $0(0.0 \%)$ & \\
\hline \multicolumn{2}{|c|}{ Shisha smoking } & $8(26.7 \%) \mathrm{a}$ & $5(16.7 \%) \mathrm{a}$ & $0(0.0 \%) b$ & $\S 0.007 *$ \\
\hline \multirow{4}{*}{$\begin{array}{l}\text { Smoking } \\
\text { index } \\
\text { ADL score }\end{array}$} & Mean \pm SD & $57.2 \pm 29.9$ & $52.8 \pm 33.2$ & \multirow[t]{2}{*}{ NA } & \multirow[t]{2}{*}{$\triangle 0.597$} \\
\hline & Range & $0.0-120.0$ & $0.0-120.0$ & & \\
\hline & Mean \pm SD & $5.6 \pm 0.6$ & $5.5 \pm 0.8$ & $5.9 \pm 0.3$ & $\wedge 0.097$ \\
\hline & Range & $4.0-6.0$ & $3.0-6.0$ & $5.0-6.0$ & \\
\hline \multicolumn{2}{|c|}{ DM } & $10(33.3 \%)$ & $10(33.3 \%)$ & $16(53.3 \%)$ & \#0.189 \\
\hline \multicolumn{2}{|c|}{ HTN } & $11(36.7 \%)$ & $12(40.0 \%)$ & $17(56.7 \%)$ & $\# 0.248$ \\
\hline \multicolumn{2}{|c|}{ ISHD } & $1(3.3 \%)$ & $5(16.7 \%)$ & $4(13.3 \%)$ & $\S 0.328$ \\
\hline \multicolumn{2}{|c|}{ Osteoarthritis } & $1(3.3 \%)$ & $1(3.3 \%)$ & $2(6.7 \%)$ & $\$ 1.000$ \\
\hline \multicolumn{2}{|c|}{$\begin{array}{c}\text { Benign prostate } \\
\text { hyperplasia (males) }\end{array}$} & $3(10.7 \%)$ & $4(16.0 \%)$ & $6(25.0 \%)$ & $\S 0.445$ \\
\hline \multicolumn{2}{|c|}{ Gastritis } & $1(3.3 \%)$ & $3(10.0 \%)$ & $4(13.3 \%)$ & $\S 0.522$ \\
\hline
\end{tabular}

^ANOVA test. \#Chi square test. §Fisher's Exact test *Significant. NA: not applicable.

Post hoc Bonferroni test (Homogenous groups had the same letter $a, b$ )

Table (2): levels of inflammatory markers among the studied groups

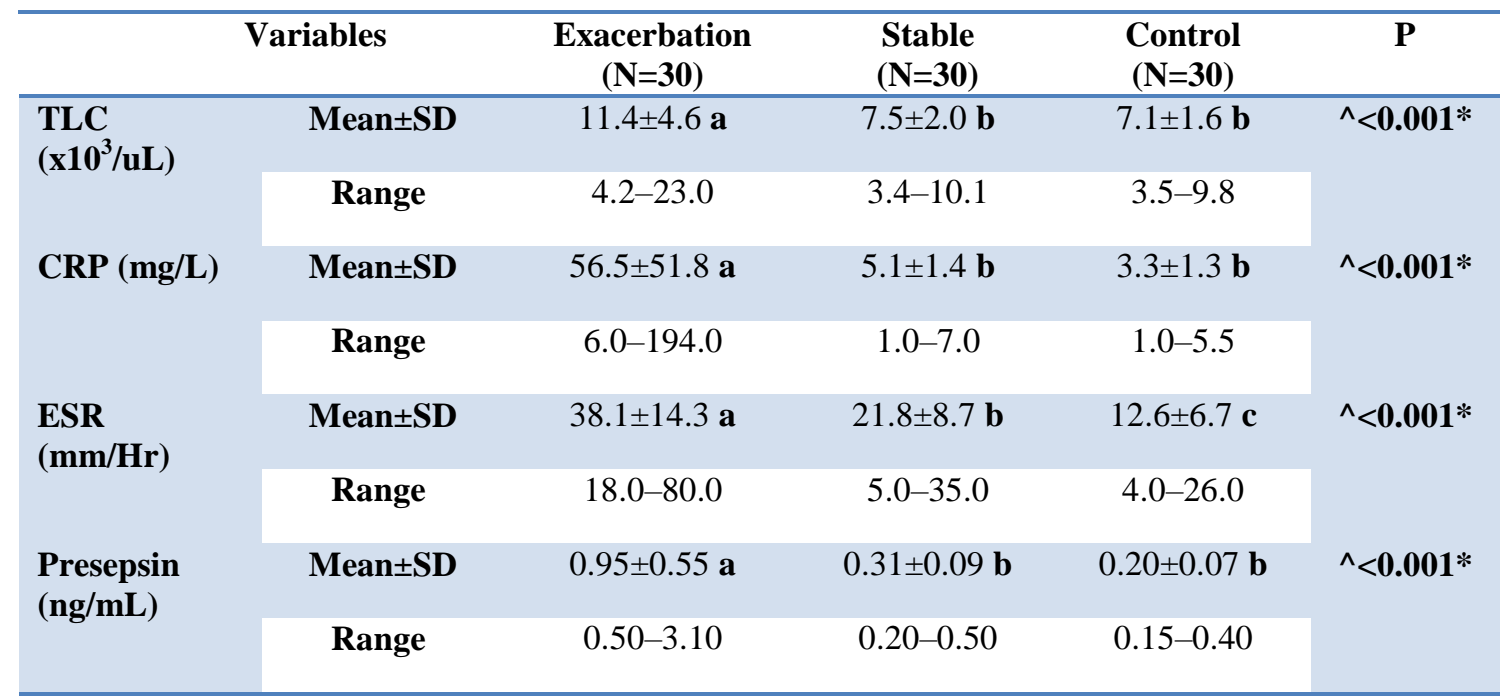

^ANOVA test. *Significant. Post hoc Bonferroni test (Homogenous groups had the same letter a, b, c) 
Figure (1): ROC curve for inflammatory markers in differentiating exacerbation from stable grou ps

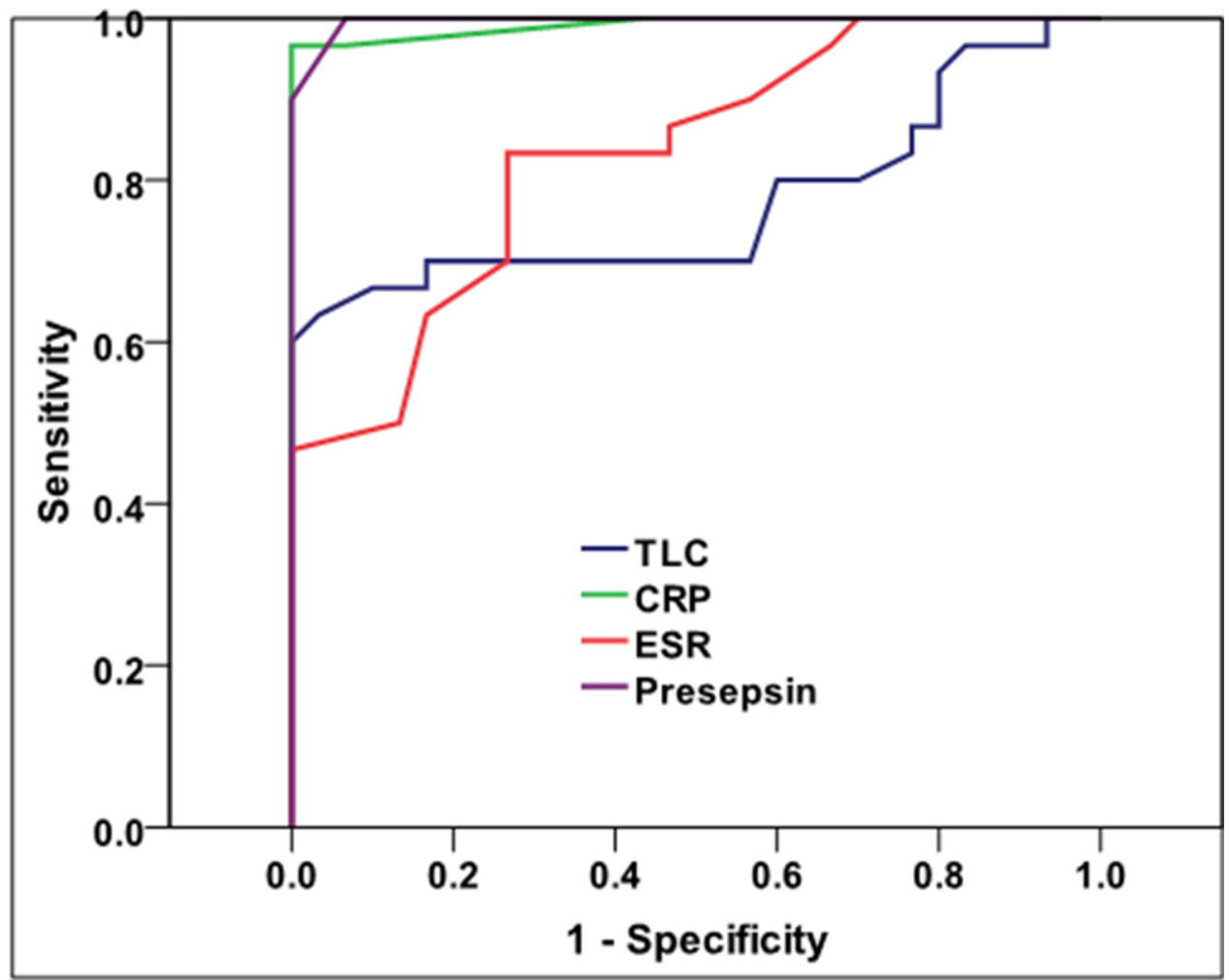

Table (3): The relation between levels of inflammatory markers and respiratory failure, ICU admission and presence of pneumonia among the exacerbation group

\begin{tabular}{|c|c|c|c|c|c|}
\hline \multicolumn{2}{|c|}{ Variables } & \multirow{2}{*}{$\begin{array}{c}\text { TLC } \\
12.5 \pm 5.6\end{array}$} & \multirow{2}{*}{$\begin{array}{c}\text { CRP } \\
79.5 \pm 63.6\end{array}$} & \multirow{2}{*}{$\begin{array}{c}\text { ESR } \\
39.6 \pm 12.9\end{array}$} & \multirow{2}{*}{$\begin{array}{c}\text { Presepsin } \\
1.2 \pm 0.7\end{array}$} \\
\hline & Present & & & & \\
\hline 苞 & Absent & $10.4 \pm 3.3$ & $36.4 \pm 27.5$ & $36.8 \pm 15.6$ & $0.7 \pm 0.2$ \\
\hline$\stackrel{0}{a}$ & $\wedge_{\mathrm{p}}$ & 0.220 & $0.031^{*}$ & 0.597 & $0.024 *$ \\
\hline \multirow[t]{3}{*}{ CXR } & $\begin{array}{l}\text { No pneumonic } \\
\text { patches }\end{array}$ & $9.4 \pm 3.1$ & $24.6 \pm 19.6$ & $34.3 \pm 16.1$ & $0.7 \pm 0.1$ \\
\hline & Pneumonic patches & $14.3 \pm 4.9$ & $104.4 \pm 48.0$ & $43.7 \pm 8.8$ & $1.4 \pm 0.7$ \\
\hline & $\wedge_{\mathrm{p}}$ & $0.002 *$ & $<0.001 *$ & 0.078 & $0.004 *$ \\
\hline \multirow{3}{*}{$\begin{array}{c}\text { ICU } \\
\text { admission }\end{array}$} & Yes & $15.1 \pm 5.3$ & $116.6 \pm 55.3$ & $41.5 \pm 12.9$ & $1.6 \pm 0.8$ \\
\hline & No & $10.0 \pm 3.5$ & $34.6 \pm 28.4$ & $36.8 \pm 14.8$ & $0.7 \pm 0.2$ \\
\hline & ${ }^{\wedge} \mathrm{p}$ & $0.005^{*}$ & $0.004^{*}$ & 0.436 & $0.016^{*}$ \\
\hline
\end{tabular}

${ }^{\wedge}$ Independent t-test. *Significant

CXR: chest X-Ray, ICU: intensive care unit 
Table (4): Correlation of inflammatory markers and clinical variables in the exacerbation group

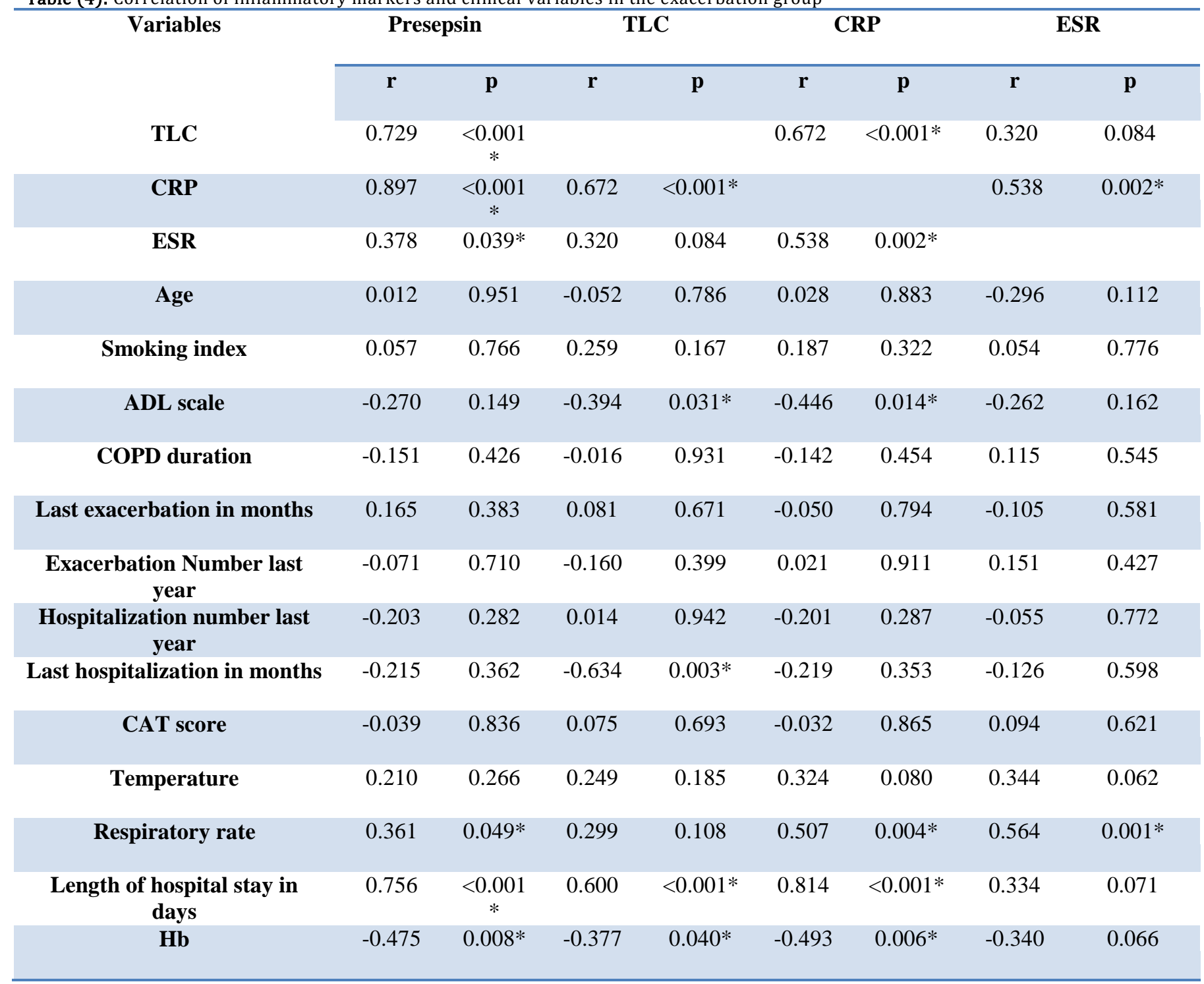

Pearson correlation. *Significant

\section{Discussion}

The aim of our study was to assess the effectiveness of presepsin in predicting COPD exacerbations which to our knowledge, had not been investigated before. However, other markers were assessed in AECOPD such as CRP, TLC, ESR, fibrinogen, PCT (procalcitonin) and suPAR (soluble urokinase-type plasminogen activator receptor). $\mathbf{2 4 , 2 5 , 2 6 , 2 7 , 2 8}$

In this case control study, we recruited 90 elderly who were divided into 3 groups; Group A: 30 patients with COPD exacerbation; Group B: 30 patients with stable COPD; and Group C: 30 control subjects.

The current study showed that after regression analysis of all studied confounding factors, prespsin, CRP and ESR were increased in stable COPD and exacerbation while TLC was increased in COPD exacerbation. Also, the cutoff values of presepsin $\geq 0.5 \mathrm{ng} / \mathrm{ml}$ and CRP $\geq 10.0 \mathrm{mg} / \mathrm{L}$ were found to have the highest diagnostic characteristics in differentiating AECOPD from stable COPD with sensitivity $100 \%$ and $96.7 \%$ respectively and specificity $93.3 \%$ and $100 \%$ respectively.

COPD is independently associated with systemic lowgrade inflammation and this inflammatory activity increases further in exacerbation states. An acute COPD exacerbation can be viewed as an acute inflammatory event superimposed on chronic inflammation associated with COPD, with bacterial infection being the cause in approximately half of the exacerbations. $^{29}$ Our findings suggest that serum 
presepsin levels have high sensitivity and specificity in displaying the inflammatory response in patients admitted with COPD exacerbation.

The results that biomarkers were found to be elevated in COPD exacerbations are consistent with the study of HURST et al. (2006) ${ }^{\mathbf{2 4}}$ who assessed 36 biomarkers in 90 subjects with COPD and found that CRP was the most selective biomarker in confirming exacerbation; however, its diagnostic accuracy was limited (area under the curve 0.73 , 95\% CI 0.66-0.8). Compared with these results, presepsin in our study was sufficiently sensitive and specific for confirming COPD exacerbation.

Similar findings were observed for PCT in the studies of Pazarli et al. (2012) $)^{26}$ and Pandey et al. (2019) ${ }^{27}$ where PCT levels were found to be significantly higher in AECOPD patients than in patients with stable COPD. Also, Gumus et al. (2015) ${ }^{28}$ found that fibrinogen, CRP, and suPAR levels were significantly higher in patients with COPD exacerbation than in healthy controls.

The finding that inflammatory markers were higher in stable COPD patients than in subjects without COPD is in accordance with other studies such as Mannino et al. (2003), Gan et al. (2004), Pinto-Plata et al. (2006), Karadag et al. (2008) and Yanbaeva et al. (2009), ${ }^{30,31,32,33,34}$ referring to the presence of inflammatory processes in stable COPD.

In the study of Eagan et al. (2010) ${ }^{35}$, CRP levels were more than twice as high in COPD patients compared to subjects without COPD. Also, Can et al. (2014) ${ }^{36}$ found that serum suPAR levels were significantly higher in stable COPD patients than in control subjects $(P<$ $0.001)$.

This study showed also that presepsin levels had significant positive correlations with length of hospital stay and respiratory rate and were significantly higher in patients with respiratory failure and in cases admitted to the ICU. This denotes that presepsin levels increase with the severity of COPD exacerbation.

This could be attributed to the positive relation between disease severity and extent of inflammation in COPD, so it is expected that inflammatory markers show elevated levels with increased exacerbation severity (Heidari B, 2012) ${ }^{37}$.

Also, in the current study, statistically significant difference was seen for presepsin, being as twice as high in COPD exacerbation patients with pneumonia $(1.4 \pm 0.7 \mathrm{ng} / \mathrm{ml})$ compared to those without $(0.7 \pm 0.1$ $\mathrm{ng} / \mathrm{ml})$. This raises the possibility that the higher the presepsin level, which is also correlated to higher CRP levels, the higher the likelihood of having bacterial infection as the cause of exacerbation.

Both exacerbation and superinfection by pneumonia in COPD patients can cause serum elevation of inflammatory markers with different levels so they can be used to differentiate COPD exacerbation from pneumonia. $^{38}$

The study of Bafadhel et al. (2011) ${ }^{38}$ showed that the biomarkers procalcitonin and CRP were elevated in patients with pneumonia compared with patients with exacerbations of asthma and COPD, suggesting that they can usefully guide antibiotic usage. Another two studies by Lacoma et al. (2011) ${ }^{39}$ and Colak et al. $(2017)^{40}$ also concluded that AECOPD patients with pneumonia had significantly higher PCT values than those without pneumonic involvement.

The current study found that elevated serum presepsin levels in patients with symptoms of COPD exacerbation are correlated with the severity of exacerbation and that high presepsin levels may also alert physicians to the possibility of pneumonia. Antibiotics are used in the treatment of exacerbations of COPD but not all patients equally experience benefit from antibiotics. COPD exacerbation patients selected on the basis of evidence of bacterial infection or by the severity of exacerbation are more likely to benefit. Using presepsin as a biomarker for guiding treatment in COPD patients ould have important implications in clinical practice as overuse of antibiotics can be substantially decreased, thereby reducing antibiotic resistance and its related side effects and lower medical costs for hospital systems and the patient. Hence, we do recommend further studies to evaluate the role of presepsin as a biomarker for targeting management and therapy of COPD patients.

\section{Conclusion:}

The current study shows that elevated presepsin levels have potential value as a robust and independent biomarker of exacerbation in COPD. Further studies are needed to figure out its potential in guiding exacerbation therapy.

Conflict of interest: The authors report no conflicts of interest in this work.

\section{References:}

1. Adeloye D, Chua S, Lee C, Basquill C, Papana A, Theodoratou E, et al. (2015): Global and regional estimates of COPD prevalence: Systematic review and meta-analysis. J Glob Health; 5(2):020415

2. Orvoen-Frija E, Benoit M, Catto M, Chambouleyron M, Duguet A, Emeriau JP, et al. (2010): Chronic obstructive pulmonary disease (COPD) in the elderly. Rev Mal Respir.; 27(8): $855-873$

3. Vestbo J, Hurd SS, Agusti AG, Jones PW, Vogelmeier C, Anzueto A, et al. (2013): Global strategy for the diagnosis, management, and prevention of chronic obstructive pulmonary disease: GOLD executive summary. Am J Respir Crit Care Med.; 187(4): 347-365.

4. Mathers CD, Loncar D (2006): Projections of global mortality and burden of disease from 2002 to 2030. PLoS Med.; 3(11): e442.

5. Lopez AD, Shibuya K, Rao C, Mathers CD, Hansell AL, Held LS, et al. (2006): Chronic obstructive pulmonary disease: current burden 
and future projections. Eur Respir J.; 27(2):397-412.

6. World Health Organization (2018): Projections of mortality and causes of death, 2016 to 2060.

7. Wedzicha JA, Singh R, Mackay AJ (2014): Acute COPD exacerbations. Clin Chest Med.; 35(1):157-163.

8. Celli BR, Barnes PJ (2007): Exacerbations of chronic obstructive pulmonary disease. Eur Respir J; 29(6):1224-1238.

9. American Thoracic Society, European Respiratory Society Task Force (2004): Standards for the Diagnosis and Management of Patients with COPD. Version 1.2. New York, NY: American Thoracic Society; 2004. Accessed January 11, 2010.

10. Singh JM, Palda VA, Stanbrook MB, Chapman KR (2002): Corticosteroid therapy for patients with acute exacerbations of chronic obstructive pulmonary disease: a systematic review. Arch Intern Med.; 162(22):2527-2536.

11. Rabe KF, Hurd S, Anzueto A, et al. (2007): Global strategy for the diagnosis, management, and prevention of chronic obstructive pulmonary disease: GOLD executive summary. Am J Respir Crit Care Med.; 176(6):532-555.

12. Chen YW, Leung JM, Sin DD (2016): A Systematic Review of Diagnostic Biomarkers of COPD Exacerbation. PLoS One; 11(7): e0158843.

13. Yoon HI, Sin DD (2011): Biomarkers of therapeutic response in patients with chronic obstructive pulmonary disease: a critical review of the literature. Drugs; 71:1821-1837.

14. Hogg JC, Chu F, Utokaparch S, et al. (2004): The nature of small-airway obstruction in chronic obstructive pulmonary disease. N Engl J Med; 350(26):2645e53.

15. Van Eeden SF, Sin DD (2008): Chronic obstructive pulmonary disease: a chronic systemic inflammatory disease. Respiration; 75(2): 224-382.

16. Sinden NJ, Stockley RA (2010): Systemic inflammation and comorbidity in COPD: a result of 'overspill' of inflammatory mediators from the lungs? Review of the evidence. Thorax; 65(10): 930-936.

17. Gan W, Man S, Senthil Selvan A, Sin D (2004): Association between chronic obstructive pulmonary disease and systemic inflammation: a systematic review and a meta-analysis. Thorax; 59: 574-580.

18. Shozushima T, Takahashi G, Matsumoto N, Kojika M, Okamura Y, Endo S (2011): Usefulness of presepsin (sCD14-ST) measurements as a marker for the diagnosis and severity of sepsis that satisfied diagnostic criteria of systemic inflammatory response syndrome. J Infect Chemother.; 17:764-769.

19. Yaegashi Y, Shirakawa K, Sato N, Suzuki Y, Kojika M, Imai S, et al. (2005): Evaluation of a newly identified soluble CD14 subtype as a marker for sepsis. J Infect Chemother.; 11:234-238.

20. Ackland GL, Prowle JR (2015): Presepsin: solving a soluble (CD14) problem in sepsis? Intensive Care Med.; 41:351-353.

21. Endo S, Suzuki Y, Takahashi G, Shozushima T, Ishikura H, Murai A, et al. (2012): Usefulness of presepsin in the diagnosis of sepsis in a multicenter prospective study. J Infect Chemother.; 18: 891-897.

22. Ulla M, Pizzolato E, Lucchiari M, Loiacono M, Soardo F, Forno D, et al. (2013): Diagnostic and prognostic value of presepsin in the management of sepsis in the emergency department: a multicenter prospective study. Crit Care;17: R168.

23. Global Initiative for Chronic Obstructive Lung Disease (2017): Global strategy for the diagnosis, management, and prevention of chronic obstructive pulmonary disease. Pocket guide to COPD diagnosis, management and prevention. A Guide for Health Care Professionals, 2017 EDITION.

24. Hurst JR, Donaldson GC, Perera WR, Wilkinson TM, Bilello JA, Hagan GW, et al. (2006): Use of plasma biomarkers at exacerbation of chronic obstructive pulmonary disease. Am J Respir Crit Care Med.; 174(8):867-874.

25. Bircan A, Gokirmak M, Kilic O, Ozturk O, Akkaya A. (2008): C-reactive protein levels in patients with chronic obstructive pulmonary disease: role of infection. Med Princ Pract.; 17: 202-208.

26. Pazarli AC, Koseoglu H, Doruk S, Sahin S, Etikan I, Celikel S, et al. (2012): Procalcitonin: Is it a predictor of noninvasive positive pressure ventilation necessity in acute chronic obstructive pulmonary disease exacerbation? J Res Med Sci.; 17(11):1047-1051.

27. Pandey S, Garg R, Kant S, Verma A, Gaur P (2019): Serum procalcitonin levels in chronic obstructive pulmonary disease patients in North Indian Population. Ann Afr Med.;18(2):103-107.

28. Gumus A, Altintas N, Cinarka H, Kirbas A, Haziroglu M, Karatas M, et al. (2015): Soluble urokinase-type plasminogen activator receptor is a novel biomarker predicting acute exacerbation in COPD. Int $\mathrm{J}$ Chron Obstruct Pulmon Dis.; 10:357-365.

29. Hatipoglu US, Aboussouan LS (2016): Treating and preventing acute exacerbations of COPD. Cleve Clin J Med.; 83(4):289-300. 
30. Mannino DM, Ford ES, Redd SC (2003): Obstructive and restrictive lung disease and markers of inflammation: data from the Third National Health and Nutrition Examination. Am J Med.; 114: 758-762.

31. Gan WQ, Man SF, Senthil selvan A, Sin DD (2004): Association between chronic obstructive pulmonary disease and systemic inflammation: a systematic review and a metaanalysis. Thorax; 59: 574-580.

32. Pinto-Plata VM, Müllerova H, Toso JF, Feudjo-Tepie M, Soriano JB, Vessey RS, et al. (2006): C-reactive protein in patients with COPD, control smokers and non-smokers. Thorax; 61: 23-28.

33. Karadag F, Kirdar S, Karul AB, Ceylan E (2008): The value of C-reactive protein as a marker of systemic inflammation in stable chronic obstructive pulmonary disease. Eur J Intern Med.; 19: 104-108.

34. Yanbaeva DG, Dentener MA, Spruit MA, Houwing-Duistermaat JJ, Kotz D, Passos VL, et al. (2009): IL6 and CRP haplotypes are associated with COPD risk and systemic inflammation: a case-control study. BMC Med Genet.; 10: 23.

35. Eagan TM, Ueland T, Wagner PD, Hardie JA, Mollnes TE, Damås JK, et al. (2010): Systemic inflammatory markers in COPD: results from the Bergen COPD Cohort Study. Eur Respir J.; 35(3):540-548.

36. Can Ü, Güzelant A, Yerlikaya FH, Yosunkaya Ş (2014): The role of serum soluble urokinasetype plasminogen activator receptor in stable chronic obstructive pulmonary disease. J Investig Med.; 62(7):938-943.

37. Heidari B (2012): The importance of Creactive protein and other inflammatory markers in patients with chronic obstructive pulmonary disease. Caspian J Intern Med.; 3(2):428-435.

38. Bafadhel M, Clark TW, Reid C, Medina MJ, Batham S, Barer MR, et al. (2011): Procalcitonin and C-reactive protein in hospitalized adult patients with communityacquired pneumonia or exacerbation of asthma or COPD. Chest; 139: 1410-8.

39. Lacoma A, Prat C, Andreo F, Lores L, RuizManzano J, Ausina V et al. (2011): Value of procalcitonin, C-reactive protein, and neopterin in exacerbations of chronic obstructive pulmonary disease. Int $\mathrm{J}$ Chron Obstruct Pulmon Dis.; 6: 157-169.

40. Colak A, Yilmaz C, Toprak B, Aktogu S (2017): Procalcitonin and CRP as biomarkers in discrimination of Community-acquired Pneumonia and Exacerbation of COPD. J Med Biochem.; 36(2):122-126. 